\title{
Experience of Application High Performance Cement Composites for Creating Durable Sculptural Elements
}

\author{
Genadijs Sahmenko, Sandis Aispurs, Aleksandrs Korjakins \\ Riga Technical University, Faculty of Civil Engineering, Institute of Materials and Structures, \\ Kipsalas street 6a, Riga, LV-1048, Latvia
}

\begin{abstract}
Traditionally, sculptural and decorative elements of building facades are created from mortar mixes based on lime, gypsum or Portland cement. Generally these materials have porous and permeable structure, which determines their accelerated degradation, especially in the aggressive environment of modern cities. High performance cement composites (HPCC) have been considered for production and restoration of sculptural elements in historical buildings. For this purpose, fine-graded, multi-component and highly workable mixes were elaborated. Mix compositions were modified with micro-fillers, plasticizing and stabilizing admixtures, as well as fibers to improve material ductility and control shrinkage cracking. Basic mechanical properties and durability (such as water absorption, frost resistance) were determined and two types of HPCC were compared (>50 MPa: HPCC and >120 MPa: UHPCC). It has been confirmed that cement composite mixes are characterized by self-consolidating effect, high compressive strength, extremely high resistance versus freezing and thawing cycles and low water absorption. Surface quality was evaluated and initial water absorption (tube tests) were performed for laboratory samples and real sculptural elements after 5 years of exploitation. The results confirmed good potential for using HPCC for creating more attractive and durable architectural shapes and façade elements compared to elements made using traditional cement and lime mortar.
\end{abstract}

Keywords: Concrete sculpture, cement composite, durability, flowability.

\section{INTRODUCTION}

Sculptural and decorative elements are an important component of building façades and urban environment element in modern cities. Their reproduction and restoration are essential for preservation of historical heritage and retention of uniqueness of cities with a rich historical past. From the first civilizations, natural stone has been used as the basic material for creating buildings and their architectural elements. Concrete is not only a popular construction material, but also the material that has been used for producing architectural shapes since ancient times. Concrete based on air hardening binder, like lime and gypsum, has increased porosity and limited mechanical strength. Perfect surface of gypsum sculptural elements is a positive property, but low water resistance and durability are essential drawbacks of gypsum binder [1]. Throughout the centuries, lime putty has been used as mortar binding agent; some lime concrete structures have preserved from ancient times. Lime mortar is a highly capillary porous material, which increases the risk of accelerated degradation of sculptural elements [2]. Ancient Romans discovered hydraulic lime cement, which consists on lime putty with pozzolanic admixtures (volcanic ash). A lot of Roman architecture monuments produced from hydraulic lime concrete survived in satisfactory conditions till present time, for example, Roman Pantheon and numerous aqueducts.

Golden Age of concrete started in the 19th century, when Portland cement was invented. Its use makes it possible to reach better mechanical strength and durability. First experiments in creating sculptural elements are dated back almost 100 years: in the early 1920th a series of 'technical' experimental cast concrete mini sculptures were created by Henry Moore [3]. The idea of exposed concrete provides for naturally exposed concrete surface. Usually, the surfaces of conventional concrete constructions contain many surface blemishes (burbles and cavities). The authors [4] proposed the improved method to evaluate surface quality by detecting blemishes in the concrete surfaces using digital analysis of the pictures of these surfaces.

The effect of moisture, freeze-thaw cycles and environment pollution are the basic reasons for degradation of architectural elements. In the maritime climate, ageing is related to chemical attack of salts [5]. In Nordic regions, moisture and freeze-thaw cycles are the dominant destroying agents, but in the Southern regions, especially in desert regions, erosion weathering and sand abrasive effect dominate. 
Shrinkage and thermal cracks are another big problem of concrete surfaces. The risk of shrinkage cracking can be minimized by shrinkage compensated admixtures as well as applying special methods of external and internal curing [6]. A lot of work and funds should be spent to repair and rehabilitate concrete using special technologies and materials [7]. Conventional concrete and mortar mixes have watercement ratio $>0.6$, it decreases mechanical properties and durability. The results of visual inspection of sculpture elements made from conventional mortar mixes show numerous defects after three years of exploitation: air voids, cavities and surface erosion after freeze-thaw cycling (Fig. 1).
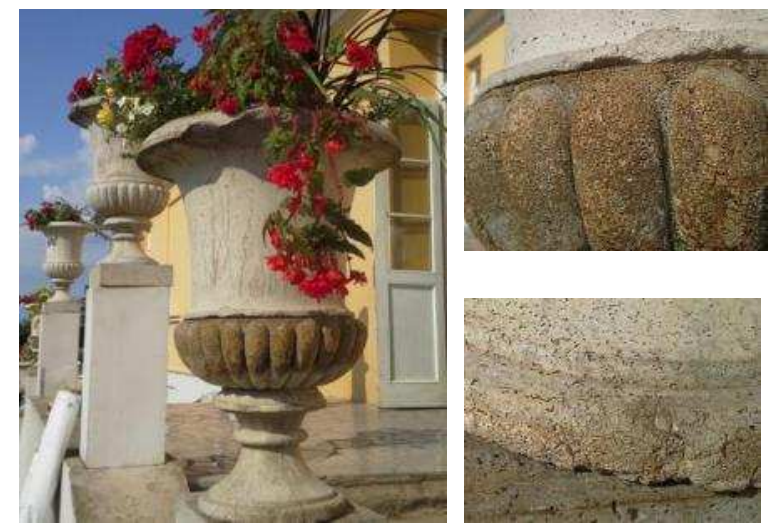

Fig. 1. Vase made from commercially available dry mix after 3 years of exploitation. Typical defects: air voids, cavities and surface erosion after freeze-thaw cycles. (Production - 2011, inspection - 2015).

The use of high performance cement composite for sculptural and decorative elements allows increasing material service time and creating aesthetic sculptural elements characterized by perfect surface and durability [8]. High performance cement composite with low water-cement ratio can provide enhanced workability and good mechanical strength. Dense microstructure is achieved by using micro and nano admixtures in optimal proportions. Insufficient ductility and fragility are compensated by adding different fibers - steel or non-metallic fibers. In accordance with the previous studies [9], steel fibers have the best effect on mechanical strength and postcracking behaviour. At the same time, some corrosion points in the element surface may appear, but this negative effect can be avoided by using polymer fibers and carbon fibers [10]. It should be noted that polymer fibers are not so effective because they have much lover modulus of elasticity comparing to steel fibers. PVA (polyvinyl alcohol) fibers are the most promotive polymer fibers with E-modulus 30-40 GPa and tensile strength close to $1 \mathrm{GPa}$. The aim of the investigation is to develop high performance cement composite for fabrication of sculptural elements intended for outdoor application.

\section{MATERIALS AND METHODS \\ A. Materials and Mix Preparation}

Two types of mixes were used: the first mix is close in mechanical properties to Ultra-High Performance Cement Composite (UHPCC), the second one is more economical - High Performance Cement Composite (HPCC) - Table 1. In the framework of experimental and practical work, local quartz-based sand (maximum particle size $-1 \mathrm{~mm}$ ) was used as a fine aggregate and gravel $2 / 8 \mathrm{~mm}$ (basically dolomite) was used as a coarse aggregate.

Silica fume and metakaolin powder were used as a micro-filling and pozzolanic admixture. Used metakaolin is an industrial by-product obtained from the manufacturing of expanded glass granules. PVA (polyvinylalcohol) as well as AR glass fibers were added in order to improve material ductility, bending strength and to decrease the risk of cracking [11]. Air entraining and plasticizing admixtures are introduced in HPCC mixes in order to improve frost resistance and durability [12], at the same time, this admixture is not needed in UHPCC mix thanks to extremely low $\mathrm{W} / \mathrm{C}$ ratio and dense microstructural packing. Mix components are summarized in Table 1. Fraction volumetric distribution demonstrates paste content 38 $\%$ in HPCC and up to $62 \%$ in UHPCC (Fig. 2).

Table I

Type Sizes, Spaces and Intervals

\begin{tabular}{|l|l|l|l|}
\hline \multicolumn{5}{|c|}{ Components } & Density & UHPCC & HPCC \\
\hline White cement CEM I & & & \\
$52.5 \mathrm{R}$ & 3.1 & 850 & - \\
\hline CEM I 42.5 N & 3.1 & - & 400 \\
\hline Sand, fractions 0/1 mm & 2.65 & 1150 & 200 \\
\hline Sand, fractions 0/4 mm & 2.65 & - & 600 \\
\hline Gravel 2/8 mm & 2.65 & - & 800 \\
\hline Silica fume & 2.2 & 140 & 10 \\
\hline Metakaolin & 2.2 & - & 50 \\
\hline Fiber PVA & 1.1 & 5 & - \\
\hline Fiber AR glass & & - & 10 \\
\hline Water & 1.0 & 210 & 200 \\
\hline Superplasticizer & 1.2 & 20 & 4 \\
Air entraining agent & & - & 0.2 \\
\hline W/C ratio & & 0.26 & 0.50 \\
\hline
\end{tabular}

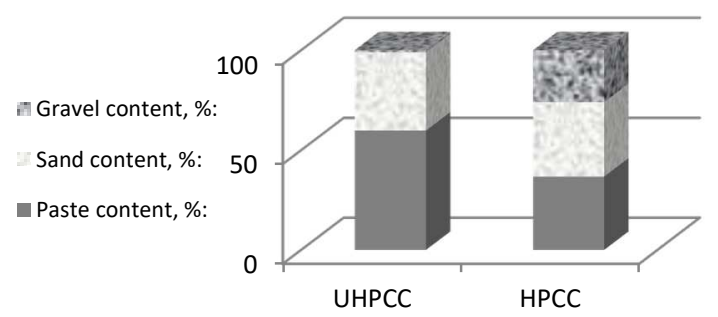

Fig. 2. Fraction volumetric distribution.

Mixing was done in a high shear motion mixer at the speed of $150 \mathrm{rpm}$. During dry components mixing, $2 / 3$ of the total volume of water was added, the mass was mixed for more than 2 minutes, then adding the rest of the water together with a superplasticizer during the mixing. Samples and sculptural elements were cured in moisture conditions 
at the temperature $+20+2^{\circ} \mathrm{C}$ for at least 28 days. Composite mix elaboration, testing and adjusting were carried out in the laboratories of Riga Technical University in collaboration with the sculptor Sandis Aispurs.

Mix flowability was determined by means of flow test, using cylinder with the internal diameter $50 \mathrm{~mm}$ and height $100 \mathrm{~mm}$. UHPCC mixes are characterizes by flowable consistency (cylinder spread 160-220 $\mathrm{mm}$ ), this makes it possible to obtain smooth surface of a concrete product. In the sculpture workshop, the elements were produced using the same technology. Numerous experiments were conducted in collaboration with Sandis Aispurs to simulate different mould surfaces and to adjust appropriate mix consistency.

\section{B. Properties Evaluation}

Surface water absorption.

Durability of exposed concrete depends on its reaction to water action. There are a several standardized methods characterizing material's water absorbing capacity: water absorption by immersing in water (ASTM C140), capillary surface absorption (NT BUILD 368), water permeability under pressure (EN 12390-8), initial surface absorption tube test (RILEM 11.4), etc. Taking into account real exploitation conditions of sculptural elements, the last method may be selected as the most acceptable. The main advantage of RILEM 11.4 test is that it may be realized both in laboratory and field conditions. In accordance with method specification, test Method RILEM II.4 is usually used to check elements temporarily subjected to the action of water.

Compressive strength was determined in accordance with EN 12390-3, using testing machine Controls 50-C56G2.

Frost resistance was tested in accordance with CEN/TS 12390-9. Cubes 100x100x100 mm were produced, matured and sawn into halves. Prior to freezing, the samples were immersed by sawn surface in $3 \%$ sodium chloride $(\mathrm{NaCl})$ solution, capillary suction period was 7 days. The samples were subjected to freezing and thawing cycles in accordance with CDF test methodology [13], duration of one cycle was 12 hours and the temperature range $20 /+20^{\circ} \mathrm{C}$.

\section{RESULTS}

A. Laboratory sample testing results

Surface water absorption test. The results of surface water absorption test confirm high difference between different types of concrete. The best results were shown by UHPCC samples: water absorption was close to zero during the first hour and only $0.6 \mathrm{ml}$ after 10 days of penetration. After 1 hour water penetration was $0.4 \mathrm{ml}$ for HPCC and close to $1.0 \mathrm{ml}$ for the reference mortar mix (produced from dry mix) (Fig. 3).

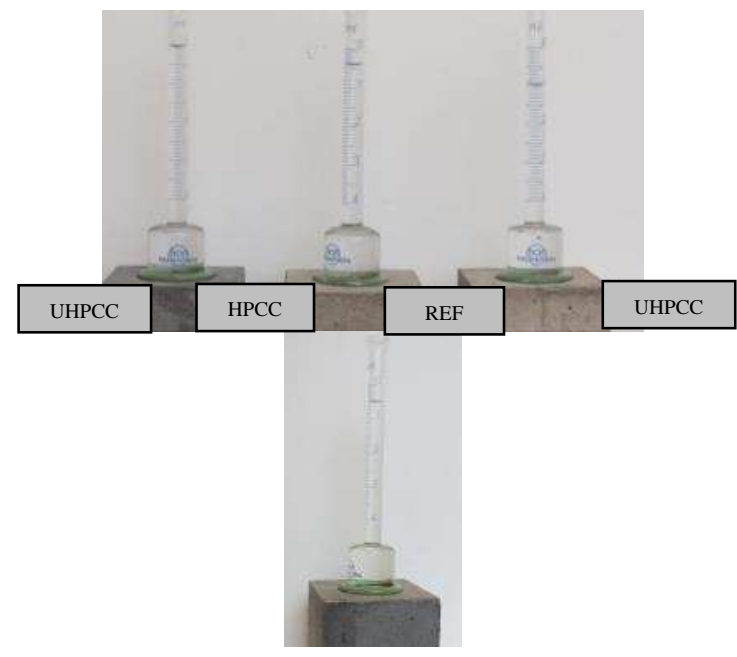

Fig. 3. Water absorption: after $1 \mathrm{~h}$ (left), after 10 days for UHPCC (right)

Compressive strength test. Compressive strength tests were performed for mix compositions produced in different times during 2 years. Results of strength and density tests are summarized in Fig. 4. Statistical evaluation shows different values of averaged squared deviation: UHPCC density demonstrates the lowest coefficient of variation $(1.7 \%)$, whereas HPCC density demonstrates higher variation (4.2\%). This fact can be explained by the effect of air entrainment, which is difficult to control. Strength results show much higher variations: $13.2 \%$ for UHPCC and $20.3 \%$ for HPCC, it may be associated with the diversity in real regimes of production and possible deviations in the properties of raw materials.
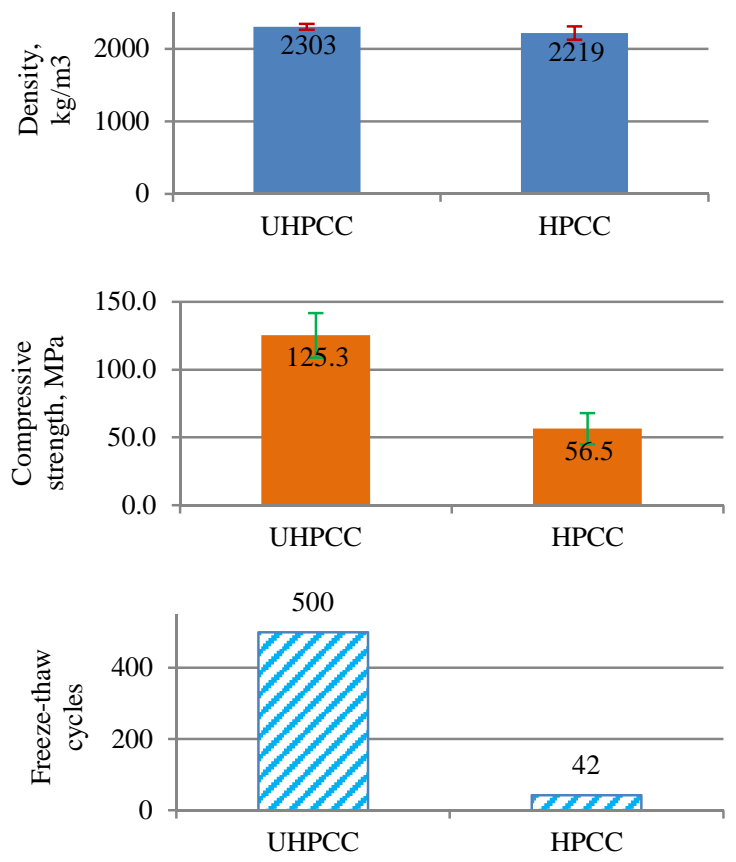

Fig. 4. Comparing density, compressive strength, their average squared deviations and frost resistance results. 
Frost resistance test. Concrete scaling resistance usually is evaluated after 28 and 56 freeze-thaw cycles. In this case, the number of cycles for UHPCC was extended up to 500 cycles, it is 18 times more than the standard requirement (Fig. 4). After the test almost no surface damage was detected (mass loss from the surface was not more than $\left.100 \mathrm{~g} / \mathrm{m}^{2}\right)$. Test results for HPCC showed lower frost resistance. After 28 cycles, the loss of mass was close to $500 \mathrm{~g} / \mathrm{m}^{2}$, but considerable destructions were detected after 50 cycles.

B. Results of inspection and testing of the installed sculptural elements

Renovation of sculptural elements was carried out by a professional artist, sculptor Sandis Aispurs [14]. The initial stage of the process included reconstruction of the sculptures in the workshop (fixed together) and modelling of the lost parts. The next stages included production of the mould [15], filling the mould and ensuring the hardening process. Complicated elements were cast in polyurethane or silicon rubber moulds, which are flexible and reusable.

Elaborated HPCC mix compositions were practically used for restoration of sculptural elements in the renovated objects in several historical buildings in Latvia. The first project was the reconstruction of concrete sculptures on the facade of Saldus Secondary School (works finished in 2015). The fronton part of the façade was initially decorated with eight concrete sculptural elements: two spheres, two vases and four sculptures made in putty style. Old elements (see Fig. 5, on the left) were completely reconstructed (Fig. 5 on the right) from UHPCC mix, using silicone moulds. After 5 years of outside use, the same vase was visually inspected and tested using Rilem 11.4 tube test. No important visual surface defects were detected and surface penetration test showed water penetration ( $1.4 \mathrm{ml}$ after 10 days), it is insignificantly more than for new UHPCC sample produced in laboratory $(0.6 \mathrm{ml}$, Fig. 2$)$.
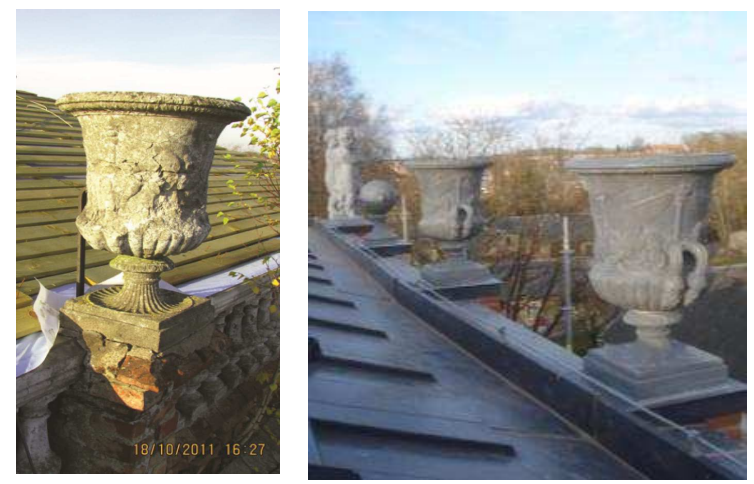

Fig. 5. Saldus Secondary School vase before reconstruction (left), reconstructed UHPCC vase (right).

Riga is one of the few European cities, which retained outstanding examples of Art Nouveau architecture buildings and design objects built at the beginning of 20th century. Therefore, Riga is included on the UNESCO World Heritage List and this city tends to be called Art Nouveau Metropolis [16]. Nowadays HPCC technology has been used for renovation of several historical Art Nouveau building façades. Usually the façades of these buildings are decorated with sculptural elements, which are considerably damaged or lost, especially the sculptures at the top of the frontons.

Among the first objects the following buildings can be mentioned: a building situated at Alberta Street 2a (described in [8]), architect Michael Eisenstein, construction completed in 1906; façade of the building at Alberta Street 7 (constructed in 1908, architect Hermanis Hilbiks) (Fig. 6); Gertrudes 19/21 (Fig. 7), Matisa Street 44. Partially damaged elements in the vertical parts of the façades were restored inplace, using special Mapei premix restoration composition (Rasa di repara). Significantly damaged elements were completely reconstructed and then
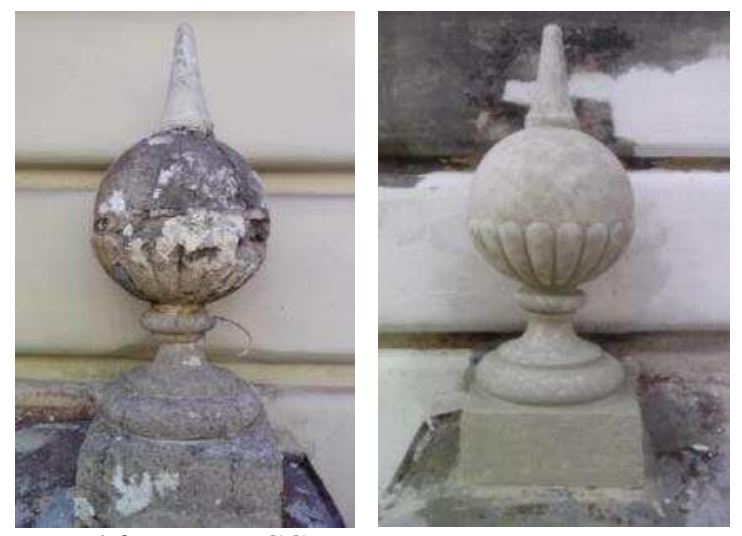

created from UHPCC.

Fig. 6. Reconstruction of a spherical sculptures in Riga, Alberta Street 7.

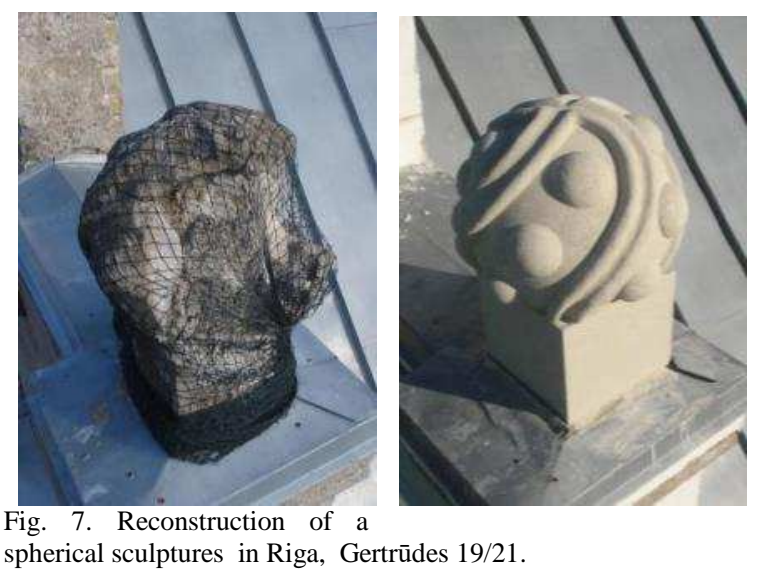

Discussing the role of PVA fiber, it must be noted that PVA fiber has a minor effect on the compressive strength and modulus of elasticity, but it improves long-term properties, such as shrinkage strains and creep behaviour [17]. It was established that PVA fibers reduce shrinkage deformations, especially in 
the early-age stages [18], [19]. At the same time, initial experiments on UHPCC samples confirm strain softening behaviour during bending test.

Current sculptor's Sandis Aispurs object is Brukna St. Apostle Chapel in Byzantine style. Basic architectural elements of the façade - columns, capitals and arches - are created from HPCC (>55 $\mathrm{MPa}$, Fig. 8). The most important current project is the sculptures of 12 apostles, which are being cast from UHPCC (>120 MPa, Fig. 9).

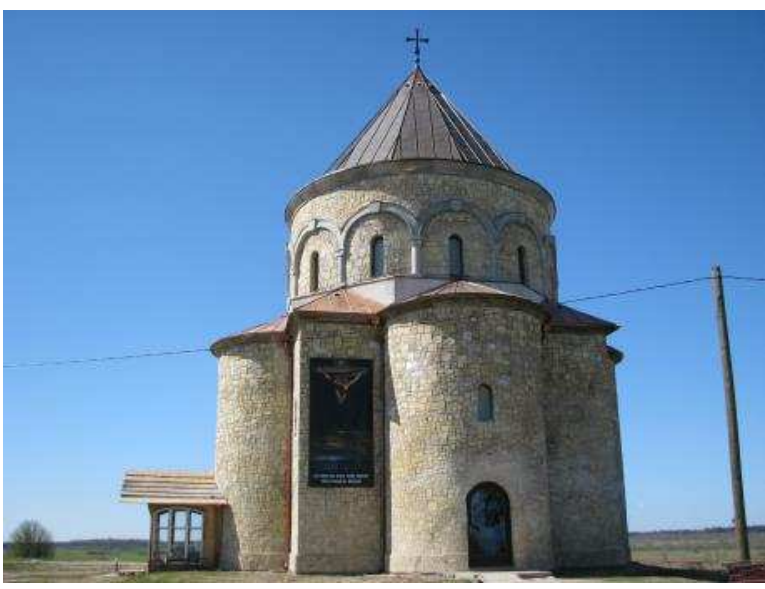

Fig. 8. Current sculptor's Sandis Aispurs object is Brukna St. Apostle Chapel (arch are produced from HPCC) (photo April, 2017).

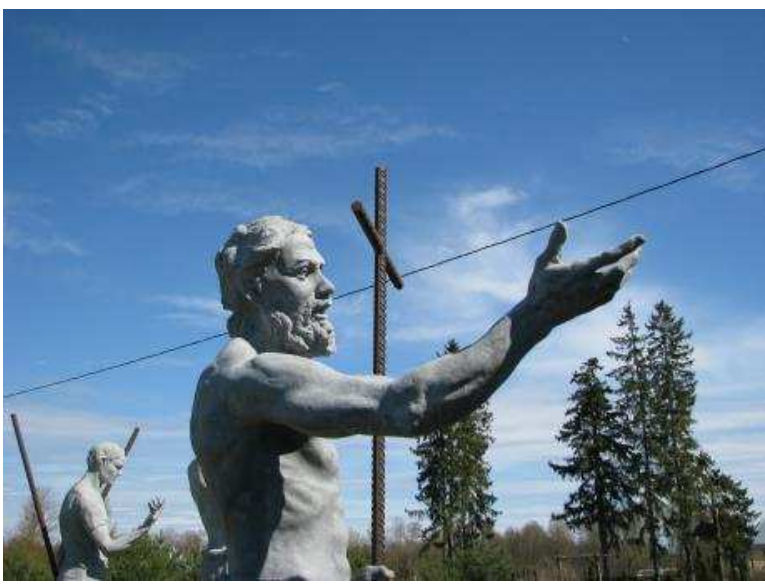

Fig. 9. Current sculptor's Sandis Aispurs works is Brukna: sculptures of 12 apostles, which are being cast from UHPCC (photo April, 2017).

\section{CONCLUSIONS}

Testing of laboratory samples and inspection of the installed sculptures made from cement composites confirm high frost durability (up to 18 times more freezing cycles comparing to traditional concrete).

RILEM 11.4 water absorption test method may be regarded as appropriate test for simple evaluation of durability of HPCC. This method can also be used for evaluating the effect of surface protective (water repellent) agents.
The use of High and Ultra High Performance Cement Composites opens new opportunities for creation and reconstruction of sculptural elements permanently subjected to open-air exploitation conditions and preservation of historical heritage.

\section{ACKNOWLEDGMENTS}

The financial support of European Regional Development Fund project Nr.1.1.1.1/16/A/007 "A New Concept for Sustainable and Nearly ZeroEnergy Buildings" is acknowledged.

\section{REFERENCES}

[1] F. Vegas and At.al., "May a building stand upon gypsum structural wall and pillars?," in 8th International masonry conference in Drezden, 2017, pp. 1-6.

[2] C. Rodríguez-navarro, "Binders in historical buildings : Traditional lime in conservation," Semin. SEM, vol. 9, pp. 91-112, 2012.

[3] R. Bailey, "Concrete Thinking for Sculpture," Parallax, vol. 21,2015 .

[4] A. Klovas and M. Daukšys, "The evaluation methods of decorative concrete horizontal surfaces quality," Medziagotyra, vol. 19, no. 3, pp. 343-348, 2013.

[5] M. Zapoyev, S. Krivoy, and S. Belyayeva, "Salt Corrosion of Masonry Mortar," Appl. Mech. Mater., no. 725-726, pp. 523-528, 2015.

[6] P. Lura, M. Wyrzykowski, C. Tang, and E. Lehmann, "Internal curing with lightweight aggregate produced from biomass-derived waste," Cem. Concr. Res., vol. 59, pp. 24 33, May 2014.

[7] W. D. Mangum, A. J. Bermudez-Goldman, D. P. Whitney, D. W. Fowler, and A. H. Meyer, "Repairing Cracks in Portland Cement Concrete Using Polymers. Final Report," no. 2, p. 122 p., 1986.

[8] G. Šahmenko, S. Aispurs, and A. Krasnikovs, "The Use of High Performance Cement Composite in Renovation and Restoration of Architectural Elements of Buildings Facades," Procedia Eng., vol. 117, no. 1, pp. 317-324, 2015.

[9] ACI Committee 544, "State-of-the-Art Report on Fiber Reinforced Concrete Reported by ACI Committee 544," ACI Struct. J., vol. 96, no. Reapproved, 2002.

[10] G. Šahmenko, A. Krasnikovs, and M. Eiduks, "Ultra High Performance Concrete Reinforced with Short Steel and Carbon Fibers," Proc. 10th Int. Sci. Pract. Conf., vol. I, pp. 193-199, 2015.

[11] A. Macanovskis, A. Krasnikovs, O. Kononova, G. Harjkova, and V. Yevstignejevs, "Mechanical Properties of Glass Fiber Composites Reinforced by Textile Fabric," Environ. Technol. Resour. Proc. Int. Sci. Pract. Conf., vol. 1, no. May, p. 133, 2015

[12] Y. Barabanshchikov, S. Belyaeva, A. Avdeeva, and M. Perez, "Fiberglass Reinforcement for Concrete," Appl. Mech. Mater., no. 725-726, pp. 475-480, 2015.

[13] C. Gehlen and A. Rahimi, "RILEM TC TDC. Compilation of Test Methods to Determine Durability of Concrete. A Critical Review," 2011.

[14] S. Aispurs, "No Title," 2017.

[15] T. J. Niel, "Process and techniques in concrete sculpture," Concr. Eng. Int., vol. 11, no. 4, pp. 46-47, 2007.

[16] J. Krastiṇš, Jūgendstils R̄̄gas arhitektūrā, Zinātne. Riga, 1980.

[17] A. Sprince, L. Pakrastinsh, B. Baskers, and L. Gaile, "Crack development research in extra fine aggregate cement composites," Vide. Tehnol. Resur. - Environ. Technol. Resour., vol. 1, no. May, p. 17770, 2015.

[18] A. E. Naaman and K. Wille, "The Path to Ultra-High Performance Fiber Reinforced Concrete ( UHP-FRC ): Five Decades of Progress," in Proceedings of HiperMat 2012 (Kassel, March 7-9, 2012), 2012, pp. 3-15. 
Genadijs Sahmenko, et al./ Environment. Technology. Resources, (2017), Volume III, 286-291

[19] N. Vatin, A. Sprince, L. Pakrastinsh, and N. Vatin, "Longterm Behaviour of Fibre Reinforced Cement Composites," in Proc. of the Second Intl. Conf. on Advances In Civil,
Structural and Mechanical Engineering- CSM 2014, 2014, no. November, pp. 116-121. 